\title{
THE CLINIC AND BEYOND
}

\section{Reproductive Temporalities}

It is not uncommon to spot statistics in IVF hospitals in Delhi that posit rather unrealistic success rates for IVF cycles. ${ }^{1}$ A few clinics even display them prominently in waiting rooms. A sign in one private hospital, for example, stated, "IVF Success Rates: 1st cycle: $40 \%$, 2nd cycle: 70\%, 3rd cycle: $90 \%$." Proclamations of success nourish hope (Franklin 1997), particularly if people encounter IVF after a long and exhaustive trajectory. In these cases, IVF often appears as a "last resort" to create "own" offspring. IVF promises not only conception (for the "quest for conception," see Inhorn 1994) but also the establishment of genealogical relations through the couple's "own" reproductive substances. What other scholars have observed with regard to surrogacy is thus true for IVF more generally: it enables "many infertile couples to 'chase the blood tie' (Ragoné 1996) in pursuit of biogenetically related offspring" (Deomampo 2016, 7).

In this context it is important to note that reproductive substances are not "mere physiological substances of reproduction but meaningful social endowments of ancestral and affinal identities and potencies" (Sahlins 2013, 65). To put it in other words, gametes carry relational potential beyond biogenetic meanings. Catherine Waldby $(2019,9)$, for example, describes how Australian women understand egg cells to be "eminently relational, linking women back into their family history, laterally into their relationships with husbands and partners, and forward into their relationships with children, actual or potential." Although egg cells are sometimes understood to connect past, present, and future in similar ways in IVF clinics in North India, sperm counts as a more powerful relational 


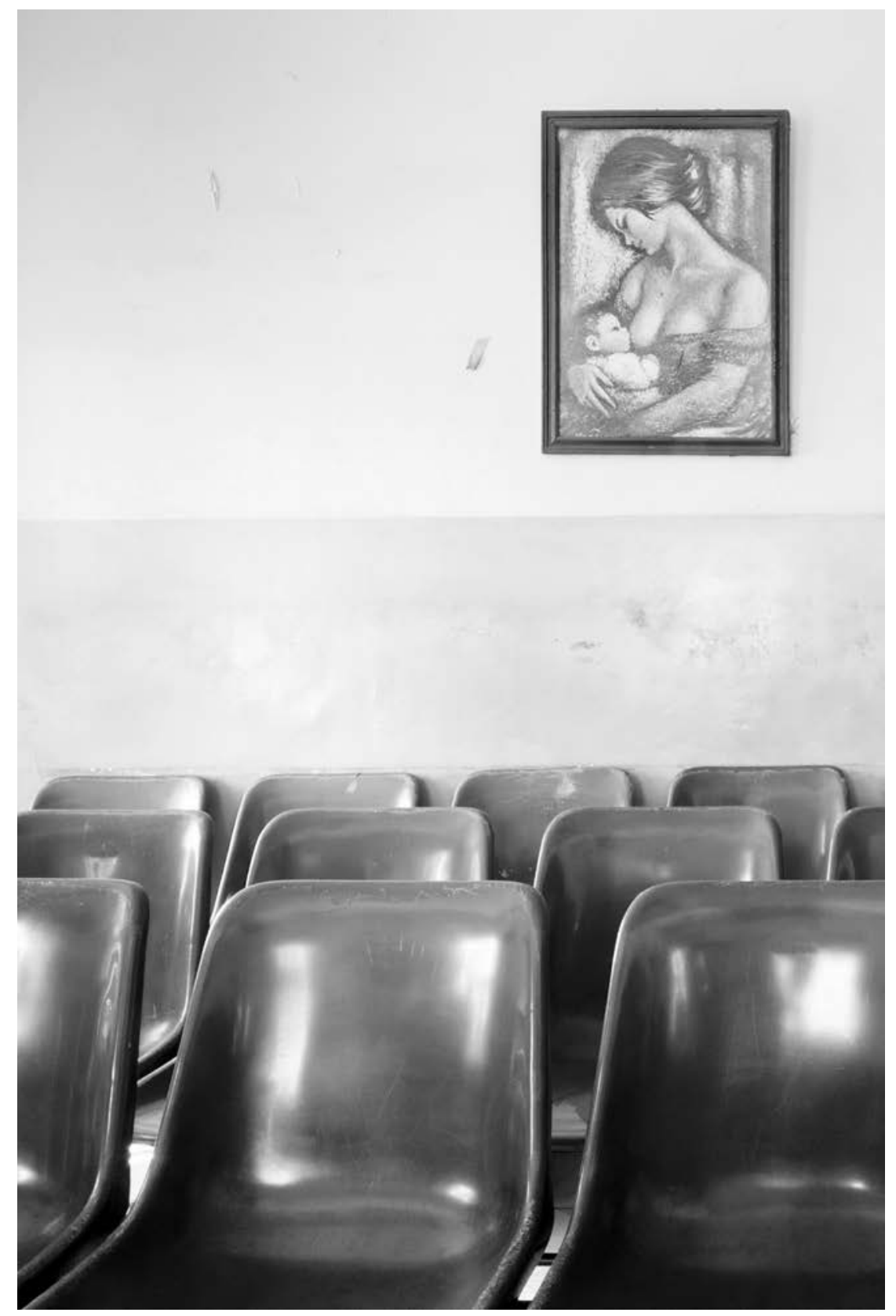

FIGURE 7. Waiting room in an IVF hospital. Photo by Chhandak Pradhan. 
substance. In predominant patrilineal perceptions, genealogical relations are created through the bond of male blood, which is transmitted through semena condensed and highly precious form of blood (for Sri Lanka, see Simpson 2004b; see also Copeman and Banerjee 2019).

In this chapter, I follow IVF patients in Delhi in their quest to establish substantial relations over time. Relying on the narratives of five IVF patients whom I have gotten to know well during my research and whom I have met several times at different stages of their reproductive trajectories, I show how their relations to infertility and medical interventions have fluctuated with the passage of time. Most patients described their treatment trajectories as convoluted and onerous paths $(r \bar{a} s t \bar{a})$. Rather than narratives of progress from infertility to completed family, "negative' temporalities of delay or failure" (Abram and Weszkalnys 2011, 14) were prominent experiences. The five narratives evolve in different ways with distinct outcomes, almost reflecting clinical statistics of success and failure. ${ }^{2}$

In addition to describing patients'-often cyclical-relationship to IVF over time, the chapter serves as an introduction to the clinical part of the IVF process, in which further dimensions of temporality come into play. Describing mundane medical practice, I observe how patients "flow through the clinic" (Inhorn $2015,26)$ and IVF cycles unfold over time. Andrea Whittaker $(2015,131)$ suggests that IVF hospitals constitute liminal spaces where "time is reorganized" and "bodily rhythms [are] regulated through pharmaceuticals and hormones." Although medical interventions are indeed designed to hormonally manipulate bodily rhythms in order to make (particularly female) bodies productive, I also show how clinical practice attunes to somatic time. Clinicians, patients, technologies, and pharmaceuticals make IVF work-not only by working on but also by working with bodies.

The chapter thus weaves together various reproductive temporalities connected to IVF: the linear quest of patients to continue genealogical relations through reproductive substances; the cyclical relationship to IVF characterized by setbacks and new trials; and the calibration of time in IVF hospitals when bodily rhythms are regulated on the one hand and medical interventions are ordered around bodily temporalities on the other.

\section{Stagnation}

What motivates people in their quest for substantial relations? For most of my interlocutors, parenthood "equal[ed] normalcy" (Becker 2000, 1) and constituted a crucial "next step" in a couple's married life. "It is very important to have a child, that is the second thing after marriage that people expect from you," remarked one woman. Not being able to take this step was experienced as a 
severe "reproductive disruption" (Inhorn 2007; see also Franklin 1997), often described in terms of stagnation. "It is time to move on," "we wanted something new in our life," or "I am ready to step into motherhood" were common statements articulated by my interlocutors. The husband of an IVF patient even invoked the four stages of the Hindu life cycle. In doing so, he located himself at the transition to the stage of a householder (grhastha) - a stage he was eager to embark on.

But infertility does not only put a couple's life on hold. It may also threaten the future of a lineage. Many patients understood it as their duty to bear offspring (see also Bharadwaj 2016). Especially newlywed women reported that they feel a moral responsibility to "give a baby" and, even better, a son to their new household, as marriage is seen to serve the prime purpose of continuing the patrilineage (vanś äge barhāne ke lie) (Singh 2017). ${ }^{3}$ Many interlocutors pointed out that "you get married in order to continue the patrilineage [vanś], that is doing your duty [dharma]." One's "own" reproductive substances, particularly semen, are of prime importance in this regard.

Additionally, some women spoke about their wish to experience pregnancy and childbearing at least once in their lifetime. I met postmenopausal patients who had already adopted a child but still tried IVF with a donor embryo in order to be able to give birth and regain their sense of womanhood. "It should be one time that I give birth, one time," explained one of them. The ability of IVF to extend reproductive time after menopause (with donor eggs or donor embryos) did not allow her to give up. As one clinician remarked, "Now a lot of older people are coming. Previously older people did not use to bother. They thought if they cannot have, they cannot have." The relatively high numbers of postmenopausal patients is related to the understanding of infertility not only as a medical but also as a moral condition. Nonconception might turn men into useless (bekār) husbands and, more often, women into barren (bānjh) wives. Women occasionally reported that they confront situations where they are not allowed to attend community functions or are shunned by neighbors and relatives because of their infertility (for descriptions of cultural conceptions of infertility and the attached stigma, see Patel 1994; Unnithan 2010; Bharadwaj 2016).

While reproductive technologies lengthen the time frame during which women are expected to bear children, the medicalization of infertility through reproductive medicine may also relieve them from blame by turning a moral concern into a medical condition. Upon entering the clinic, infertility turns into a disease that can be diagnosed and potentially cured. Especially the routinization of semen analysis helped to shift structures of blame from women experiencing the sole responsibility of childlessness toward at least considering the possibility that the "fault" might lie with the husband. While, as many doctors recounted, 
a few years ago many men were not even willing to provide a semen sample for medical analysis, it has since turned into a routine procedure. And in cases in which semen quantity or quality were defined as below average, dynamics between couples often changed. One doctor even employed the strategy to never explicitly state that the semen is "good" in order to avoid the "blame game." While I have seen both partners expressing feelings of inadequacy or insecurity when the medical diagnosis indicated their "fault," only women ever voiced the fear of grave consequences, such as divorce and the husband's remarriage (see also Inhorn 1996). Puja, a patient I met in CommonCare, had faced these threats from her mother-in-law.

\section{Puja}

As she visibly enjoyed telling, Puja had met her husband under adventurous circumstances. It was a "love marriage" that her mother-in-law had opposed from the beginning. Puja, a teacher and beautician, was too educated for her mother-in-law's taste-she would have preferred a "village girl." Hence, trouble was foreseeable, but her mother-in-law's harassment intensified when no offspring was in sight-a particularly urgent issue for the family, as Puja's husband is the eldest son. Luckily for Puja, her husband could not be convinced to remarry. "My mother-in-law told my husband to leave me and get married again but my husband refused." Later on, she urged Puja to do whatever it took to give birth to a grandchild. "She told me that there were so many different procedures to get pregnant, and I should pick one of them." Seven years later, after nothing had worked, the mother-in-law threw Puja and her husband out of the house.

I met Puja in the tiny home that she and her husband had built in a poor neighborhood in the far west of Delhi. She had already undergone one unsuccessful IVF cycle in CommonCare and was currently contemplating another. Even though her husband would rather leave this topic once and for all, Puja was now consumed by it.

He says that I should not bother for all this, and there are people who live without kids. But at the end of the day, women have this feeling in their heart to have a baby of their own. . . My husband tells me to leave all this but I am sure I will get him to agree. We just built this house so we are low on cash these days. .. . We have some loans to pay off, but once they are done...

Puja believed that she would be able to arrange the sum she would need for a second IVF cycle through her participation in a women's self-help group. The women in the organization support each other by providing a certain amount of money every 
month to assist one of them with a project (for an example of raising money for IVF with bingo events, see Roberts 2012, 74).

As Puja's story demonstrates, it is not only the obligation to produce offspring that makes people mobilize large financial resources. Long after the family had already broken up over the issue, Puja still tried to conceive. Other patients I talked to also expressed a strong desire to have children in order to overcome feelings of absence and loneliness. Children were considered to "complete" the couple and "make life meaningful" (Bärnreuther 2019). They wished to care for someone and have "something to look forward to" when returning from work, like Neha, whom I will introduce in more detail later on:

I come home and there is nothing to look forward to except cook food, cook dinner, and go to bed. Get up in the morning and go to work. So it is that thing that is missing. Bringing up a child, helping him with his studies. There is nothing to look forward to. First you are looking forward to getting married, then you get married. Then you look forward to having another change in your life, which is your children. Then you grow with your children. In our lives we have nothing to do. All we look forward to is switching jobs or planning a vacation but then we are lonely at the end of our day. Although we are happy with each other. $\mathrm{He}$ [Neha's husband] is quite happy, he doesn't miss anything in life, he does not feel any void, but I do feel that.

Reproduction proved to be important in several respects for my interlocutors: it may provide a family with offspring and continue the family line, but it may also mean the fulfillment of a personal desire and constitute an important step in a couple's relationship. "Reproduction involves many actors and competing pulls of duty, desire, and care" (Singh 2017, 24). Social expectations, familial demands, and personal desires are often inextricably entangled, and all conglomerate in the need to have one's "own" child. To Puja and Neha, childlessness presented itself as a condemnation to stagnation within their lives, relationships, and families (for the United States, see Becker 1994; for the United Kingdom, see Franklin 1997). But rather than considering alternative means of reproduction, such as adoption (Bharadwaj 2003), both pursued their quest for substantial relations through medical interventions.

\section{The Right Time}

Infertility is recognized as a medical condition by the World Health Organization (WHO) and, among other factors, it is defined temporally. The clinical description 
developed in 2009 characterizes infertility as "a disease of the reproductive system defined by the failure to achieve a clinical pregnancy after 12 months or more of regular unprotected sexual intercourse" (Zegers-Hochschild et al. 2009, 1522). Or, in another WHO document (2010), infertility is defined as "the inability of a sexually active, non-contracepting couple to achieve pregnancy in one year." Besides the inability to conceive, the common basis of both definitions is the time span of twelve months. Infertility, hence, stands out from other medical conditions in that it is characterized not only by specific symptoms but by its duration over a certain period of time.

The temporal dimension mentioned in the WHO definitions incidentally overlaps with the point of time when many couples in India start to experience their reproductive life as problematic and consider consulting specialists. Interlocutors reported that if there was no "happy news" between a few months and two years after their marriage, they would undertake "first steps." During my research, I only met couples who identified as married, and, if not otherwise indicated by patients, doctors took the wedding as the starting point of their efforts to conceive. Couples who used contraceptive methods after their marriage counted the time from the moment when they started "trying for a child."

The right time to seek medical interventions is determined not only by the amount of time that has elapsed since starting to "try" but also by the amount of "social pressure" people face. My interlocutors described social pressure as manifesting itself either openly by manner of exclusion and stigmatization or in more subtle ways, for example in the form of suggestions to "do something"-whether conducting rituals $(p \bar{u} j \bar{a})$, visiting auspicious places, or consulting doctors. Pressure may prompt couples to undertake a higher number of interventions or start with procedures earlier than initially intended. For example, a couple I met in PremiumIVF had decided to not immediately undergo an IVF cycle after learning about the wife's blocked tubes. They had planned to first enjoy their time alone together and focus on their careers. But pressure from their family eventually led them to pre-pone their IVF cycle: "We are not in a hurry ... But in India you are pushed into parenthood as soon as you get married because of familial and social pressure. We don't have any issues [to wait] but it is custom," the husband justified their decision.

As well as constituting an element that drives patients into doctors' chambers, time serves as a major criterion in medical decision-making processes. When new patients arrived in the consultation room, and doctors noted down their reproductive history, the first questions they posed were, "How long have you been married?" and "Since how long have you been trying for a child?" In doing so, they established whether the medical definition of infertility applied and what kinds of interventions were justified. When recently married couples 
visited the clinic, doctors would send them home with the instruction to try for a few more months. ${ }^{4}$ Natural conception, they explained, is not an easy process and it might require a few months till "it clicks." Couples who turned up after a few years of childlessness, however, were often reprimanded for coming in "so late."

Another temporal factor that figures prominently in medical decision-making is the age of the female patient. In biomedical understanding, female bodies possess only a certain number of egg cells that are eventually exhausted over the course of a woman's reproductive life (Martin 1987). The age of the female patient thus determines the urgency of interventions. Yet the so-called chronological age of a patient does not necessarily overlap with her gynecological age - that is, the state of her ovarian reserve. Hormonal and other tests are therefore employed as "time planners." They are understood to trace the progressive decline of fertility and aid in decisions about whether and how soon IVF should be undertaken. In order to determine appropriate medical procedures, doctors thus employ various temporal measurements: the time since the couple started trying for a child, the chronological age of the female patient, and her gynecological age. These constitute guidelines for diagnosis as well as the appropriate progression of interventions.

Not all patients visiting IVF clinics receive a definite medical diagnosis (e.g., blocked ovarian tubes). Oftentimes their state is labeled "unexplained infertility." In cases where routine diagnostic procedures yield no results and the underlying reasons of infertility remain unclear, doctors suggest trying a specific order of interventions. In these cases, suitable fertility management is conceived of as a process of trial and error that ideally unfolds at an appropriate speed. After conducting initial tests and monitoring cycles, doctors might start with stimulated cycles (i.e., only prescribing hormones for ovarian stimulation). Later, they might conduct IUIs before advising patients to undergo IVF. ${ }^{6}$ In this scheme, IVF itself may eventually serve as a means of diagnosis (Franklin 1997, 146), as it may expose otherwise hidden flaws, such as bad egg quality or dysfunctional fertilization. The temporal relation between diagnosis and treatment is inversed in these cases, as diagnosis happens retrospectively as part of the treatment regime. Or, as Gay Becker $(2000,16)$ puts it, "the proliferation of assisted reproductive technologies has led to a paradigm shift in which infertility care is driven not by the diagnosis, but by the treatment."

There are rules of thumb about how many cycles of a particular intervention one would try in a row; after five to six unsuccessful cycles of IUI, most doctors suggest patients to "move on" to IVF. Yet the "right" point in time is not easy to determine: patients and doctors have to walk the fine line between progressing to possibly unnecessary, invasive, and expensive interventions too soon, and losing 
time by proceeding too slowly-or "wasting time in being conservative," as one doctor put it (for the United States, see Becker 2000, 17). Many patients felt that they had lost precious time during earlier stages of their treatment trajectories (see also Whittaker 2015, 105). When they eventually were advised to use IVF, many decided to take their chance.

\section{Treatment Rhythms}

An IVF treatment cycle unfolds in specific rhythms. It starts with ovarian stimulation, a procedure during which clinicians administer hormonal pharmaceuticals to female patients in order to achieve the growth of several follicles that contain egg cells. While this stage of the cycle is designed to hormonally manipulate the female body in order to make it productive, clinical practice also attunes to bodily rhythms. For example, ovarian stimulation can only start on day two or three after the onset of menstruation. In case patients visit the clinic at other points of time, doctors ask them to return on day two of the next cycle. In this sense, the body's monthly reproductive cycle predetermines the time frame within which medical procedures can be conducted.

One strategy to bypass the specific rhythms of patients' bodies is the "downregulation" or "suppression" of their menstrual cycles with oral contraceptives. Downregulation turns the reproductive body into a "clean slate," as doctors call it, which can then be manipulated according to clinical schedules by adding hormones. This method is used when clinicians conduct IVF in a "batch system," where the reproductive cycles of various patients have to by synchronized.7 This is necessary if hospitals employ freelancing embryologists who are available only for a couple of days per month, so that egg cell retrievals and embryo transfers of all patients have to happen on the same day. ${ }^{8}$ Yet many doctors criticize the batch system as not taking into account peculiarities of individual bodies, as Dr. Isha, a junior doctor in PremiumIVF, explained. "Sometimes the hormones rise early and then the patients ask, 'Why don't we do it [the retrieval] now?' So what to tell them?" Hence, even if bodies can be refashioned in ways that are convenient to clinicians, they might not deviate entirely from their idiosyncratic rhythms-a fact that clinicians have to adapt to and work with.

At times, patients request doctors to start their IVF cycle within a specific time frame (e.g., in a particular month or after a certain date), according to advice from astrologers. As one patient explained, "We do things parallel, we do not only rely on one method. Celestial bodies influence your fate. My mother-in-law asked an astrologer, according to the birth charts. He told us that in September and October there is a good time for trying, so we thought it would be a 
good opportunity to do IVF now." Besides that, more down-to-earth concerns are taken into consideration as well: one day when Dr. Isha was in the middle of determining the approximate timing for an IVF cycle, the patient suddenly interrupted her calculations. "Actually, could we move it to next month? I don't want the child's birthday to be in the summer ... it's too hot for birthday parties." When starting the ovarian stimulation process, doctors thus have to calibrate different temporal logics relevant in IVF clinics (Thompson 2005, 9-10): bodily processes, clinical schedules, astral configurations, or even future birthday parties.

During ovarian stimulation, hormonal pharmaceuticals are administered to patients on a daily basis through injections. Their impact on patients' ovaries is overseen by vaginal ultrasound examinations, which are the primary means in a complex regime of monitoring to capture the so-called "response" of bodies. ${ }^{9}$ When patients enter the darkened ultrasound room and hurriedly undress in one corner, the doctors assembled flip through their medical files. As soon as the preparations are completed, and the patient's body is placed on the couch where the scans take place, it has entered "clinical territorium" (Heimerl 2013, 72), meaning it becomes available for clinical inspection. After the insertion of the ultrasound probe, the clinicians' eyes immediately turn to the glimmering screen of the scanner conveying a constantly shifting black and white image. For patients, the screen is invisible, as it is placed behind their head. And in contrast to prenatal scans, during which doctors sometimes provide elaborate explanations, patients are usually ignored during monitoring sessions. This is corroborated by their behavior: most of them distance themselves from the goings-on in the room by remaining silent, looking at the ceiling, or closing their eyes (78). Eventually, a picture of the reproductive tract appears on the screen, in which follicles, which contain egg cells, are discernable as dark circles. Once a segment of the ovaries that encompasses most of the growing follicles is brought into focus, the image is frozen. This provides clinicians with the possibility of measuring the diameters of follicles by plotting a line across the black structure in the picture. The numbers that appear on the computer screen are noted down on monitoring charts. They enable comparative assessments over time and are used to determine the pace of follicular growth. These results, in turn, elicit specific instructions from physicians. Based on these figures, clinicians take decisions about dose adjustment, which they briefly communicate to patients, simultaneously noting down their instructions in medical records.

If a patient's body responds well to the pharmaceuticals, which means a gradual growth of multiple follicles, the dosage continues. In case follicles grow in a pace considered to be too fast or too slow, the pharmaceutical regime is adjusted accordingly. Thus, although the female body is manipulated and monitored through pharmaceuticals and technologies, the body's response simultaneously 
dictates medical interventions. Many doctors therefore consider IVF not only as a set of practices shaping bodies but also as a process during which they have to pay careful attention to them. At the same time as they fashion bodies, doctors listen to them. "Let's see what your body says," or "it depends on the response of your body," were frequent comments uttered in hospitals. Hence, while patients themselves remain quite silent during the time of ovarian stimulation-some authors even argue that they become "collaborators" in their medicalization (Whittaker 2015, 107; see also Thompson 2005)-their bodies turn into responsive entities, engaging with and contributing to biomedical practice.

Just to be clear: bodies do not adhere to a communicational model of signalresponse (Martin 1987, 40), which suggests that pharmaceutical input according to fixed protocols is directly translated into a certain somatic output. In CommonCare, for example, clinicians were always pressed to explain to the central supply agency that they simply cannot determine the required amount of hormonal pharmaceuticals, as it varies between bodies. While there surely are clinicians who employ standardized stimulation protocols, most of the doctors I worked with disdained this approach. Years of experience enabled them to relate to every body in distinct ways: they carefully listened to and were in turn responsive to patients' bodies in a constant modulating process of finding the right dose that results in the right response. For example, when Dr. Nishika started working for a corporate hospital in which protocols were standardized, she refused to use the fixed doses suggested by the management of the hospital. "Every patient is different," she explained. "It is not just a technique where you are just doing something without evaluating, without thinking. Every couple is an individual couple rather than a factory setting. You cannot conduct this like an assembly line." She therefore continued to design ovarian stimulation protocols customized for particular patients' bodies. This constant back-and-forth between clinical manipulation and somatic response surpasses simple mechanisms of stimulus-response, as responsive bodies constantly demand creative adaptations from physicians. During ovarian stimulation, doctors thus work not only on but also with bodies in order to turn them into productive entities.

In cases in which clinicians encounter bodies that are not responsive, medical procedures are discontinued. For example, in case a body does not respond to ovarian stimulation in a productive way, all procedures are stopped and a rhetoric of stagnation (e.g., "sleeping ovaries") and even lifelessness is employed, reflecting prevailing concepts of infertility as an unproductive state (Martin 1987). "It is of no use to beat a dead horse," was Dr. Isha's answer to a situation when a treatment cycle had to be abandoned because a patient's body had not presented itself as responsive. She made it clear that it is not in the clinician's power to change these situations: "We can only work with what nature has provided us.... If there 
are no eggs, you cannot bring them up." Thus, only those bodies that exhibit sufficient and adequate growth of follicles in terms of quantity and pace are valued as being capable of undergoing assisted reproduction. ${ }^{10}$

Once follicles reach a certain size, patients receive a "trigger" shot of hCG to finalize maturation. Roughly thirty-six hours later, just prior to the expected time of ovulation, egg retrieval is scheduled. At the same day when eggs are extracted from the woman's body during a small surgical procedure, her partner "collects" semen in the hospital. The prepared egg and sperm cells are then fertilized in the lab either in a petri dish (IVF) or through micromanipulation (ICSI). A few days later, the resulting embryos are transferred to the uterus during a procedure that resembles a pelvic exam. Exactly two weeks after embryo transfer, a pregnancy test is conducted. These stages of the IVF cycle constitute a predefined sequence, almost a treatment rhythm with which patients become familiar. "I am very comfortable with the cycle, I know what's going to happen, I know what to expect," said Neha after her fourth IVF cycle. Time, in this scheme, is highly structured: it is expressed in segments of months, days, or hours and can be visualized on calendars in a linear way.

While this form of clocked time prevails as a hegemonic mode of temporal measurement in the clinic, it is rather unhelpful in expressing patients' experiences of an IVF cycle. Duration between treatment events is not necessarily perceived in terms of equal time bits; rather, time may stretch or contract (Serres 1998,60 ). While some phases of IVF cycles may pass by very quickly, others may appear endless. The most poignant example for the experience of stretched time are the two weeks between embryo transfer and pregnancy test, a time of high anxiety about whether implantation has occurred or not. While the IVF process before embryo transfer is characterized by constant monitoring, these two weeks are defined by ambiguity. The state of the embryos transferred to the uterus cannot be visualized by ultrasound or hormonal tests, since they do not produce any meaningful traces yet. As one patient explained, "Beyond the transfer there is nothing that can be monitored for two weeks. You can feel changes inside, sometimes there are cramps and you just don't know what is happening. I wish they would come up with some monitoring process during this time." Since clinicians cannot elicit medically intelligible data during these two weeks, every patient is treated as potentially pregnant: the medications continue, and they are only stopped if the pregnancy test turns out negative. Many patients corroborate these measures with their own precautions: when returning from the embryo transfer in the operation theater to the recovery room, they move slowly, swaying from one foot to the other and holding their abdomen to prevent the embryos from "falling." Some also take leave from their jobs, avoid abortive food, and spend the time till the pregnancy test resting at their mother's house, like many pregnant 
women in North India who return to their natal home (for similar precautions in Thailand, see Whittaker 2015, 117). This period of waiting seems to last forever and plays an incisive role for the experience of IVF cycles as exceptional.

In general, IVF represents an experience out of ordinary time for many couples. It puts routine life on hold (Becker 2000, 176; Franklin 1997, 168) and reschedules daily activities. "Now it is work that revolves around doctors' appointments, not the other way round," remarked one patient. Many people even quit their jobs or took leaves: "I quit my job, because I thought that it will add to the stress and I can be more concentrated on that [IVF]. And it is difficult with office: you have to wait for hours [in the hospital], then you have to go upstairs to get injections, it takes a whole day. And you have to do frequent visits." For most patients medical interventions become a priority in their lives for a couple of months or even years (Bärnreuther 2019). However, when IVF cycles are successful, normality is regained soon after. In the twelfth week of pregnancy, most IVF centers transfer their patients to a "normal" obstetric department in a "normal" hospital where delivery will take place. ${ }^{11}$ Many patients are thus able to normalize their exceptional experiences in retrospect. As the brother of an IVF patient put it once his sister's baby had been born: "Now it is yours, it is not IVF anymore." But when IVF cycles remain without positive results, different dynamics unfold.

\section{Setbacks}

Although, numerically, failure constitutes the norm, patients whose pregnancy tests turn out to be negative experience the lack of success as a severe setback. They often described surprise and disappointment when they realized that their body has failed them once again. "There was so much emptiness, frustration, so much waste," said a patient whose IVF cycle had failed earlier. "Now I don't consider it anymore as the end of my life," she continued. "It cannot be an endless journey. It is not in my hands. But this feeling of sorrow is always going to be there." Amita, as well, had to cope with disappointment not only because her IVF cycle had failed but also because her body had only produced a low number of egg cells.

\section{Amita}

When I met Amita and Vivek in PremiumIVF in 2012, they were very hopeful that their current IVF cycle would work out. It was the day of their egg cell retrieval, and in the morning they had stopped at a temple to receive blessings 
for the procedure. Doctors and IVF can only help to a certain extent, they said, everything else is in god's hands.

After their arranged marriage four years ago, Amita followed Vivek to the United States-the country where he had studied and then worked as an engineer. When they returned to India one year after their marriage, people immediately started to ask questions about their reproductive status. They therefore decided to consult a doctor: first, Amita had several cysts removed from her uterus, and then they tried IUIs for a while. Since nothing happened, their gynecologist eventually referred them to PremiumIVF. During our first encounter Amita had already told me that she experienced IVF as an exhaustive and invasive procedure. This was related to the fact that her ovarian reserve turned out to be low, and that she had to endure an exceptionally long time of ovarian stimulation.

As I found out during our second meeting, their pregnancy test had been negative. Amita was shocked about the result, which she perceived as a double failure: not only the IVF cycle but also the ovarian stimulation had not been very successful. "I could produce only three eggs, despite all the assistance and the medication. There is nothing wrong with my husband. One [egg cell] was not healthy, one was [grade] $A$ and one was [grade] B. They transferred these [last] two. We trusted them and did not question anything." Especially since she had put so much trust in her doctors, Amita was disappointed about the clinicians' indifference when the cycle failed. "Doctors were very indifferent. I would just have needed a pat on the back, nothing big. I did not even get to see the senior doctor. Just one of the junior doctors who came and explained, 'The test is negative, you have three options now: one, two, three. Take as much time as you need and come back to us.' I still have those papers. But I never went back. I got really attached to the people [the doctors] and then it turned out to be really commercial." What was disappointing for Amita was not only the fact that her hopes had been shattered but just as well that her doctors did not provide sufficient emotional support.

Like Amita, many patients "appeared prepared for the rigours of the discipline that the 'clinical gaze' imposed on the body, as long it was confined to the manipulation of the 'anatomical body' and did not extend to include the doctor/patient interaction. In that respect, patients sought a softening of the 'gaze"' (Bharadwaj 2016, 222). After they had spent much time in hospitals and they became familiar with their doctors, many patients felt betrayed when cycles failed. They were frustrated that doctors could not pinpoint exact reasons and provide sufficient explanations. As Dr. Nishika noted,

I always tell them [her patients] that [positive] results are not more than 35 to 40 percent, and the reasons can be this, this, this. So everything has 
been discussed. They already know. And yet they will ask this question.... But unfortunately in reproductive medicine there is nothing like this. Even when there is a clear-cut factor, like tubal factor, when the [fallopian] tubes are damaged, there can still be an implantation factor [in addition]. It is very difficult to pinpoint exactly where the problem is. You can only know that your ovarian tubes are the only problem, if your treatment is successful.... There are too many gray areas in reproductive medicine.

Although IVF enables the circumvention of certain problematic factors (e.g., bypassing blocked fallopian tubes), reproductive processes that are neither observable nor controllable, such as implantation, can still thwart success. Hence, it can only be verified in retrospect, after a successful treatment cycle, that the suspected factor constituted the only problem.

Since there are a lot of gray areas in reproductive medicine, as Dr. Nishika suggested, surprises occur frequently in IVF hospitals. Doctors often described the procedure as a "lottery," "gamble," or "Russian roulette" (for patients' use of gambling metaphors, see Becker 2000, 126). Sheryl de Lacey $(2002,46)$ points out that the metaphor of a lottery, which is also employed in IVF clinics in Australia, produces two binary subject positions: winners and losers. ${ }^{12}$ Similarly in Delhi, with the difference that winning or losing the game was not always considered to be a mere coincidence, as Neha explained.

So many failures and on the face of it, I am not suffering from any major kind of infertility issue. Whatever I am facing is medically treatable, but still I am not able to have it. Definitely it is my destiny involved. There are people with even worse cases than me and they conceive, and I am not able to conceive. Out of ten patients probably I am one of the topmost hope-giving patients to a doctor. "She is one of the top ones, who has the highest ability of getting pregnant." But then I don't get pregnant. And I realize it is my destiny. Something is not right.

Patients as well as doctors often activate modes of retroactive ascription after IVF failures: the search for causes reaches not only back to the treatment cycle but further into the past. Failures are analyzed by referring to destiny (kismat) and karma, as connective elements between past moral responsibility and future fate that manifest in present conditions (Babb 1983, 179). ${ }^{13}$ Dr. Bhavana, for example, stated, "We have a saying: first your destiny was written, and then your body was formed. Which means, right from the time of conception, your destiny has been 
written." In this sense, the infertile body constitutes a visible sign of past deeds and a site where destiny has inscribed itself.

However, this does not mean that patients stoically accept the failure of a treatment cycle as a sign of their future infertile fate. At the same time as the past has a bearing on the present, the present may influence the future. Babb (173) makes a similar point with regard to theories of misfortune that are "concerned, at least implicitly, with the future as well as the present and the past.... On the one hand, such a theory is retrospective, pointing backwards in time to events that shaped the present; on the other hand, it looks ahead to a future that can be influenced by actions taken now." As Dr. Bhavana explained, "Suppose you have hurt somebody in your previous life, or you've done this wrong, then you will be paying for your sins in the next life. So, there are certain things that you can do penance for. Even in this life."

Apart from reference to destiny or karma, god (ūparvālā or bhagvān) is also called on to explain the results of cycles. If IVF works, one patient reasoned, it is "god's way of giving you what you cannot have. We have no control. It is what it is." Another patient even deployed detailed calculations of success: "Good luck, plus strong determination, plus god's cooperation means success.

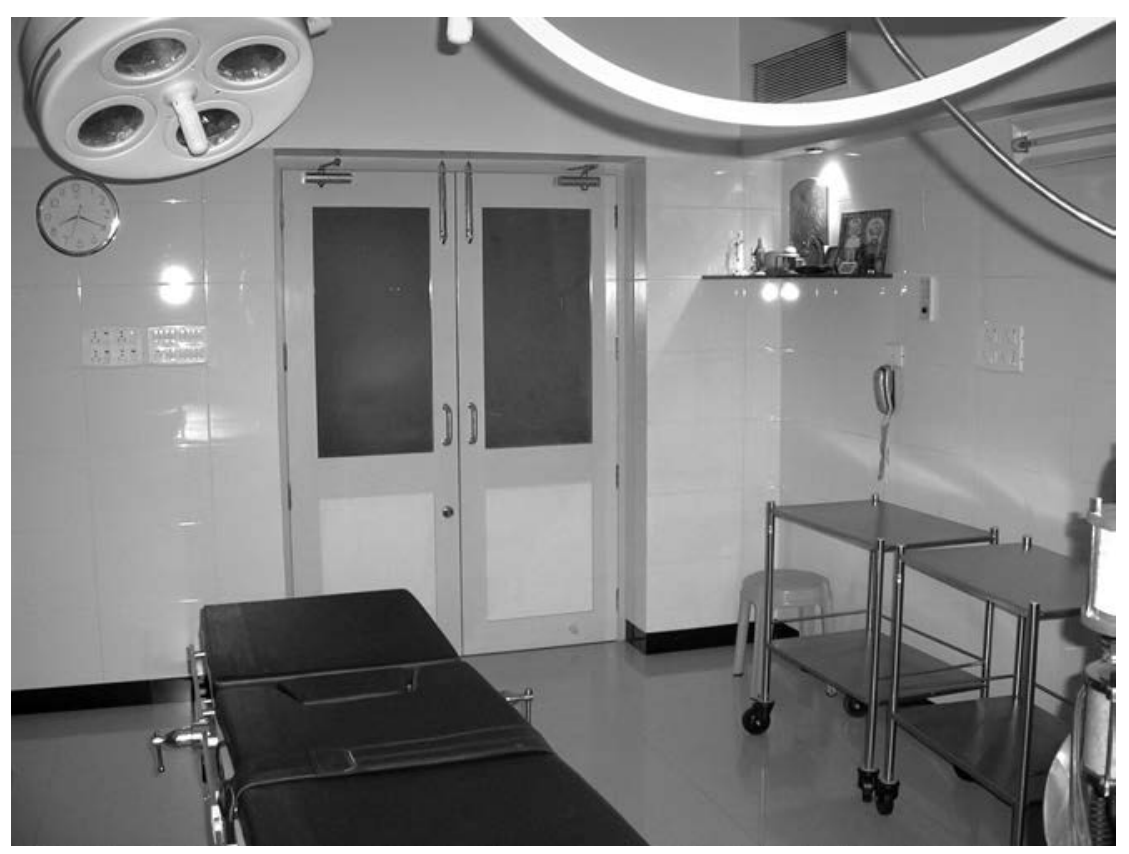

FIGURE 8. Operation theater in an IVF hospital with gods displayed in one corner. Photo by the author. 
This is my equation." Doctors too invoked help during procedures and urged patients to remember god (e.g., bhagvān ko yād karo) for IVF to work better. Particularly the time after embryo transfer, when no further medical steps are possible and the two-week period of waiting begins, was perceived by many to be a time "where god takes over." Or, as a patient put it, "After ET [embryo transfer], everything is god or destiny." 14 In this sense, both patients and clinicians understood "the process of assisting nature itself [as in need of] assistance" (Bharadwaj 2016, 233).

And indeed, many IVF cycles fail. In these cases, doctors try to maintain the semblance of normality. They advise patients to have a break and then consult them again: "Your test is negative. Stop all medications now and wait for your period. Whenever you are ready for another cycle, come back at your second day [of the period]." However, couples often need more time to recover-not only physically but also psychologically and financially, as Amita, for example:

This [the IVF failure] had a huge psychological impact on me. I felt frustrated. And even worse because I stay with my in-laws. They put a lot of pressure and blamed me in the sense of "you did not do this and that, maybe it would have been fine otherwise." But my husband was very supportive and patient, he also told them that they should stop.... My mother-in-law said immediately, "You should take another shot." And I was like, "Nobody thinks about me!" I really needed a break. It took me six to seven months to get over this. I was frustrated, went into a depression, all felt negative. I stopped praying. I put on a lot of weight and I felt really ugly and negative. Financially you can recover from this by working more, but psychologically ...

Decisions on how to proceed take time. In the end, however, IVF often remains the only viable option for patients in their quest to establish substantial relations. This is the reason why many couples eventually return to the clinic to try once again. Amita as well started to think about another cycle, as she told me during one of our meetings: "I have now taken one and a half years of break. ... Now I am again contemplating since the beginning of this year. Because my husband is not fine with adoption and nothing else happens. I am afraid that I will get too old and don't have the energy anymore to bring up a child." In this sense, decision-making processes often resemble cycles (Franklin 1997, 157; Wilson $2014,2)$ : from hope to disappointment, to doubts and deliberations, and finally to new hope and a new attempt. 


\section{Cycles of Hope}

IVF trajectories usually don't end with the failure of one cycle; rather, if financial means are available, failure constitutes the starting point of a new attempt. Despite low success rates, many patients in private hospitals mobilized large amounts of money to undergo several cycles. In the public hospital, where IVF is free but pharmaceuticals are still expensive, one cycle often exhausted patients' sparse resources. And yet, people were willing to take loans or sell land and jewelry just to try one more time.

\section{Neha}

Neha was in the middle of her third IVF cycle when we had our first conversation in PremiumIVF. As she and her husband told me, they did not have a structured plan, but kept on following advice from doctors, friends, and family: "We went ahead without much thinking." Married since 2004 and trying for a child since 2005, they decided to visit a gynecologist in 2006. The initial tests indicated that Neha had a hormonal "imbalance," PCOS (polycystic ovarian syndrome, which is an endocrine disorder often associated with infertility), and one blocked tube. After nine unsuccessful cycles of ovulation induction combined with timed intercourse, Neha was referred to PremiumIVF. Like most other patients, the couple had also tried several other methods: Neha had fasted every Wednesday, she had turned vegetarian for several months, and they had gone on pilgrimages. To improve her hormonal values Neha also tried acupressure sessions for a couple of months. But in the end, she reasoned, "For us this [IVF] is the only way out."

Dr. Nishika conducted their first IVF cycle in 2007, which failed. A couple of months later Neha visited the recently opened IVF unit of CommonCare because she knew the doctor in charge. This enabled her to circumvent long lines and waiting hours. The pregnancy test, however, turned out to be negative as well. Two years later Neha and her husband decided to try IVF for a third time. They first visited a prominent doctor in Mumbai but eventually decided to conclude the cycle in PremiumIVF, which was also not successful. After this third cycle Neha decided to take a break. And, if she ever underwent IVF again, she reasoned, it would be only with donor eggs, as egg quality had been a problem in all her cycles.

Neha had a strong sense of guilt toward her husband. She regretted not being "able to give him children" and mentioned that he would have been better off if he had married another woman. While Neha's husband was more than reassuring that their childlessness would not change his feelings towards her, he still persuaded Neha to give it one more try. Thus, she underwent another IVF cycle with her own eggs in combination with LIT (lymphocyte immunization therapy) 
in a recently opened corporate hospital in Gurgaon, which also failed. LIT is an immunological therapy, where the white blood cells of Neha's husband are injected into her-a highly experimental and controversial therapy that is banned in several countries.

We had seen an ad in a newspaper offering free consultations, so my husband said we will just go and talk to them. I wasn't ready, I said no. I said, "If I want to get something done, I get a donor egg." I wasn't ready to go for a normal IVF at all. He said, "Let's go and ask, we will not go for a treatment, we will just seek opinion, what they have to say." .. But you know, once you meet somebody and somebody gives you a shimmer of hope. Then you say, "Ok, why not." So that is the reason. And after my fourth failed attempt I said I am never going to do it again, never again. It is more than six months now and again somebody tells me why don't you try it once again. That kind of a thing. Every time I say no, but then something happens and things change.

Although Neha had decided not to continue with fertility interventions after the fourth failure, a couple of months later doubts rose again and she contemplated another possible option: a third-party IVF cycle with donor eggs. "After four IVFs, my only hope is a donor egg. That is the only thing I have not tried yet. I just have to make up my mind to go in for a donor egg." Even though breaks between treatment cycles had grown larger, the thought about trying continued to emerge. "Most likely, if I have to again think about it, I will go in for donor, not my own eggs anymore.... This is what is on my mind, this is on the agenda for this year. I am going to turn thirty-six now, so it is time to make decisions."

What prompts patients like Neha to spend an enormous amount of time and resources on a procedure as uncertain as IVF? Neha cited the "shimmer of hope" that compelled her to undergo cycle after cycle. "If I have hope," she told me, "I would do it. If I even have 10 percent hope, I would do it." Hope is palpable in various ways when visiting IVF hospitals, for example in the form of (sometimes exaggerated) success rates that manage to translate an uncertain event into a tangible figure. Hope is further nourished by thank-you cards from patients and photographs of babies, all neatly pinned to the walls of waiting rooms. Slogans, such as "Yes! You can have a baby" or "Way to parenthood made easy" are also frequently displayed in clinics.

Although "[t]o have or to 'live in' hope means to take an active stance towards the future so that the possibilities and potentiality inherent in the present may be rendered achievable" (Novas 2006, 291), hope constitutes a double-edged sword 
for IVF patients: "enabling women to continue and dis-abling them from reaching an endpoint of treatment" (Franklin 1997, 192). I have to note, however, that doctors in PremiumIVF and CommonCare did not explicitly "sell hope" (Becker $2000,116)$ in consultations but made an effort to downplay patients' expectations. "It is not like using a credit card: you don't dip the card and immediately get a baby," Dr. Isha explained. I often witnessed fierce discussions when she tried to make clear to patients that there is no guarantee for a positive outcome: "It is so difficult to make them understand that this is not 100 percent," fumed Dr. Isha after such a consultation. And Dr. Nishika continuously emphasized that IVF cannot be called an efficient treatment, almost so that she as a clinician has lost hope in it:

I think the [medical] understanding even in so many years has not progressed as it should, and we are still very much behind in calling it [IVF] an efficient treatment. It is not an efficient treatment. Any treatment which doesn't even give 50 percent results, you can hardly call it efficient. So there is a lot more to understand before we can say, "Yes, this is it, you know. This is it, what we are offering will give the patient a good hope of pregnancy." So we are not there yet. ... It started with a lot of hope, but then over the years we haven't moved fast.

But physicians also justified practicing IVF, despite its uncertainty, through the few successful cases they were able to enter in the books. Dr. Aishwa, for example, explained that "inability to conceive is something very stressful and very demoralizing for the patient. And unfortunately, success is not 100 percent. But at least we have to try. At least we made a few [patients] pregnant, which otherwise would not have become pregnant."

Whether doctors explicitly sell hope or not, it is fueled at any rate through the temporal logic of successive cycles. Treatment cycles don't unfold in a repetitive way. Rather, clinicians make sure to always change a feature or add another technique during a new cycle in order to demonstrate progress, such as LIT in Neha's case. And the possibilities of add-ons are numerous: different ovarian stimulation protocols, ICSI, donor gametes, or surrogacy arrangements. "There are so many options now of trying for a child, which always provide a ray of hope. If this does not work, then there is donation or surrogacy and all different combinations," explained Neha. New techniques incite new hope that it might work this time with this particular procedure. This mixture of promise and hope prompts many patients to embark on one IVF cycle after another. And since hope hardly ever loosens its grip, it leaves them stuck in a vortex of treatment cycles, failures, and new trials. 


\section{Time to Stop}

Similar to infertility as an experience "out of synchrony" (Becker 2000, 117) or as a liminal period from which couples cannot move on to parenthood, IVF itself creates another form of liminality (Franklin 1997): many patients get caught in a series of treatment cycles from which they can only extricate themselves through their own decision to stop. Most clinicians do not explicitly tell patients to end interventions, as Dr. Lakshmi exemplified. "I always tell the patient, 'You have come to me with a desire, not with a disease. And it is up to you to what extent you want to go ahead and fulfill your desire. You have to draw the line." For patients, however, this proves to be a tricky endeavor. "The paradox at the heart of this quest for conception is that, while the infertile critique medical interventions as unsatisfactory, they continue to endure them in the absence of any tangible alternatives" (Bharadwaj 2016, 211).

When I contacted patients one or two years after I had first met them in IVF clinics, I was surprised at first that most of those who were still childless were willing to talk to me again. During our conversations I realized that they did so because IVF was not a closed chapter in their lives. They deliberated whether to go for another IVF cycle, add another feature, or try another doctor. They pondered over possible reasons why it had not worked for them, and they were curious about my opinion regarding hospitals. Even when people had decided to go ahead with adoption, short interjections like, "maybe we should have tried once again," made it clear that the idea of IVF had not been shelved completely. Sometimes, this led to apparently retrograde decisions. Couples who had already set their mind on adoption or who had already adopted a child returned to IVF clinics only to try once more, hoping to finally succeed in their quest for substantial relations. The few people I met who were able to stop IVF were the ones who either eventually had a child or suffered severe complications from the procedure.

\section{Urshita}

Urshita was one of the few patients whose IVF cycles had failed but who had made peace with her reproductive trajectory. She was able to do so because she eventually conceived on her own and had a son. She was one of those so-called miracle cases where conception happened naturally after failed IVF cycles. ${ }^{15}$

This was the third time Urshita had invited me to her house-a different one each time. It seemed that she keeps on moving with her husband and her father-inlaw from one housing society to the other within the newly developing areas of the National Capital Region. The construction of the apartment block in which they 
were living at that time was not yet finished. Gray walls awaited their whitewash, and the shopping and sport facilities were still far from being inaugurated. Their decision to buy this apartment had happened all of a sudden, Urshita told me, "like everything in my life." Another instance where Urshita's resoluteness had manifested itself was when her family arranged for her marriage in a middle-sized town at the foothills of the Himalayas. The agent they had employed was supposed to propose several suitable candidates to her and her family. Urshita, however, liked the first man whose profile she saw and decided to stop her search right there.

Similarly, Urshita maintained her firm decision not to undertake any more attempts after one fresh and one frozen failed IVF cycle. The day she learned that her second pregnancy test (from the frozen embryo transfer) was negative, she was so disappointed that she remained in the car while her husband and mother sat through the session with the doctors, who recommended that she undertake another attempt one month later. When she called me after a few days to tell me about the result, she had already made up her mind not to follow this advice. "I need a break. I have taken medications for two years now. There are side effects. Doctors take the easy way and tell you to try it again. But they don't have to take the injections. It is burdensome, also emotionally and psychologically. And it is expensive." Taking this decision was by no means an easy task. Urshita's motherin-law, who had been living with them, had often articulated her wish to see the child of her only son. And maybe Urshita would have thought about another attempt if she had not conceived naturally after a few months-despite her diagnosis of blocked tubes.

Seven years after her wedding, she gave birth to a son. Her husband was still agitated over the fact that the doctors had told them that they could not conceive naturally. He was tempted to return to the hospital to show their son as a vivid proof of their error. Urshita, however, tried to forget those difficult times filled with hospital visits and medications. "I don't want to think about IVF anymore. Those were dark times." It was noticeable though that Urshita refused to be determined by her past IVF experience in decisions about her future reproductive trajectory. Shortly after the birth of her son, Urshita got pregnant again, much to her surprise. She and her husband were not sure whether they wanted another child. Further, the "spacing" to their first son seemed too narrow to them. Spacing-the temporal distance between children-is an important aspect in family planning in India. Therefore, they decided to abort and try for another child later. "If it happens, fine, if not then we have him," Urshita concluded.

There are, however, IVF failures that do not end as happily as Urshita's story. Tara, for example, was one of the few women who completely broke with IVF 
without conceiving, because of severe side effects. Often neglected is the fact that IVF includes not only the risk of failure but also the risk of major health complications. $^{16}$

\section{Tara}

Tara met her husband, Kapil, during their college days. They married a few years later, but were not particularly keen on having children right away even though there was a lot of pressure from Kapil's parents, as their only other son and his wife had problems conceiving. However, as soon as they found out about Tara's PCOS during a routine check-up, they started consulting doctors: "Initially for me, because also there was an issue [with infertility] for Kapil's brother, there was kind of a pressure on me. From day one of my marriage I was told that 'you get us a baby, make us grandparents.' We did not take it very seriously. But after we found out about PCOS we actually pressed the panic button. So yes, I wanted to conceive and I wanted to become a mother. That was the logical next step for us."

After several stimulated and monitored cycles as well as a couple of IUIs that remained unsuccessful, Tara had been preparing very diligently for her IVF cycle in a private clinic in Gurgaon, a satellite city of Delhi and part of the National Capital Region: she had stopped smoking, taken leave from her job, and aligned her daily schedule to injection timings. When I met her for the first time through a common friend, she was extremely optimistic and looked forward to this new option that would help her become pregnant. However, during the treatment cycle, Tara had to be admitted to the hospital with OHSS (ovarian hyperstimulation syndrome). OHSS is one of the possible risks recorded on informed consent forms and recited quickly to every patient before the procedure. Resulting from high doses of hormonal pharmaceuticals, it can become life-threatening.

Almost two years later, Tara recalled the events that led to her failed IVF cycle: everything seemed to be perfectly fine until the embryo transfer. Her doctor was content with the number of egg cells and praised the morphology of the embryos as looking "just as in science books." But the morning after her embryo transfer Tara started to complain about breathlessness to her husband, who immediately took her to the hospital. Tara remembered, "They said it is alright, it happens at times, take a puff or two. Then I came back home. Two days later again I had a very major attack, and I was rushed back and admitted. Dr. Vibhuti is the gynecologist, and her husband is a physician [who treated her for OHSS]. I still remember that I was concerned about the baby, in case there is any development, but he said, 'No, my first priority now is to save your life.' Because there was a lot of water. They took out seven liters of water from my body, from my lungs and other cavities." After a few days, Tara recovered. Her pregnancy test, however, turned out to be negative. 
Furthermore, all the costs resulting from the complications had to be borne by Tara and Kapil-a considerable expense. Tara's disappointment was still visible in the way she stored her medical reports in her apartment in Gurgaon. While all her preIVF records were neatly arranged, and she had even drawn up a table with dates of interventions and prescribed medications, the papers of her IVF cycle were cluttered and had started going moldy. "This was for the IVF. I never touched this bag again," she remarked while trying to sort through the papers.

IVF not only constituted a medical disappointment but had greater repercussions on Tara's life: for a few months after the treatment Tara suffered from severe acne, and she also gained a lot of weight. She was contemplating quitting her job when her boss started delaying her salary, but she stayed on because she knew that a new employer might not grant her the necessary leaves, if she ever wanted to go for another IVF cycle. When I met her, Tara seemed hopeless and directionless: "I feel like my life is at standstill at the moment. Usually you have something to look forward to: college, careers, children. But I have the feeling that there is nothing for me right now." She reaffirmed this feeling a year later when she reflected about this time: "There was nothing to look forward to, and that is a sad feeling. I used to at times feel that my life is just this, it should end now. Not that I was getting suicidal, but I felt that whatever I had to do in my life is done, now it is one drag."

Even though Tara is still not sure about how to proceed, she is certain that she will never try IVF again. "You saw me in a bad phase of my life," she told me several years after the incident. "I will not do this to myself and my body anymore. Then I was in a huge mental agony. I am still trying to come out of it, mentally and physically. It took also a toll on Kapil and me as a couple. It is a huge cost that I paid."

Although Tara managed to stop IVF, it proved to be a painful process. Since it implies the opportunity for a new beginning, failure paradoxically constitutes "the force through which dreams and desires for the future are renewed" (Cross 2014, 23). Hence, rejecting a new attempt at IVF, even after failed cycles, is tantamount to shattering one's dreams and contenting oneself with an alternative future, devoid of substantial relations.

Although clearly exaggerated, the "IVF success rates," as they were displayed in a private hospital in Delhi, guide patients in their quest for substantial relations. Generating hope, the logic of success rates seduces patients to proceed with medical interventions. But the establishment of genealogical continuity through IVF is rarely straightforward. As the five narratives have shown, reproductive trajectories of infertile couples cannot be understood as progressive flows toward a fertile future; rather, they constitute convoluted and onerous paths that are infused with negative temporalities. 
In addition to describing patients' relationship to IVF over time, the chapter observed how IVF cycles unfold in specific rhythms. I demonstrated how clinical interventions, such as ovarian stimulation, are designed to manipulate female bodies in order to make them productive and valuable for IVF. However, bodies do not simply obey medical practice but respond and interfere-they "kick back" (Barad 1998, 112). Or, as Emilia Sanabria (2016) put it, bodies are plastic: malleable and resisting. They make their presence felt in clinical life through different modes of somatic activity that materialize in the form of temporality, productivity, and unpredictability. ${ }^{17}$ Bodies' engagement with medical practice during ovarian stimulation demands responsiveness from physicians and may compel them to attune to somatic rhythms-a topic to which I return in chapter 6. In the next chapter, I argue that IVF is not only valued but also feared for its promise to generate substantial relations. 